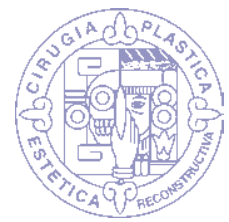

\title{
El renacimiento de la cirugía plástica
}

\author{
The renaissance of plastic surgery
}

\author{
Dra. Estela Vélez-Benítez*
}

A casi dos años de haber iniciado la pandemia de la enfermedad por coronavirus 2019 (COVID-19), el tiempo se detuvo, vivimos incertidumbre, miedo, escasez y desabasto, pérdida de conocidos, colegas, amigos y familiares, por lo que tuvimos que aprender, evolucionar; reinventarnos, renacer y desarrollar una nueva manera de vivir; para continuar con un nuevo estilo de vida y adaptarnos en el medio en el que vivimos, en la vida cotidiana y en nuestra práctica médica.

Al inicio de esta pandemia, las cirugías electivas no urgentes se pospusieron. Muchos sistemas hospitalarios cambiaron a un modelo de estándares de atención de crisis, lo que requiere un cambio en las operaciones habituales de la atención médica. A través del tiempo y de los meses, tuvimos que estudiar la enfermedad y continuar con nuestras actividades cotidianas, ya que ninguna enfermedad tiene un soporte económico. Tuvimos que hacer cambios en nuestras relaciones interpersonales, en nuestra vida cotidiana y práctica médica.

Todo esto nos recuerda epidemias pasadas, así como la cirugía plástica de la Edad Media, ese tiempo en el que la cirugía plástica retrocedió, prohibiendo realizar cirugías, al considerar este tipo de intervenciones no dignas de los médicos, incluso con la pandemia de la peste se evitaba el contacto con los enfermos. Sin embargo, con el humanismo renacentista surge un esplendor en la ciencia, la medicina y la cirugía plástica, desarrollán- dose varias técnicas quirúrgicas, analgésicas y de antisepsia.

En el consultorio y en el quirófano desarrollamos nuevas estrategias como la evaluación de pacientes con el apoyo de la telemedicina y consultas virtuales a distancia. Establecimos reglas y uso de equipos de protección para poder atender y operar de acuerdo con la nueva clasificación de pacientes: COVID, no COVID y post-COVID; incluso algunos de nosotros atendimos a pacientes de primera línea con el uso de un cubrebocas o cobertura facial para protección, y hemos sido más estrictos con la asepsia y desinfección de espacios, mobiliario, manos y objetos.

Aprendimos a identificar y evaluar riesgos y medidas de seguridad, con recomendaciones de asociaciones médicas asiáticas y europeas, quienes fueron los primeros con experiencia en pacientes COVID. En México, nuestra Asociación de Cirugía Plástica, Estética y Reconstructiva emitió una serie de recomendaciones para la seguridad de nuestros pacientes, de nuestro personal y de nosotros mismos con la finalidad de evitar el contagio de la enfermedad, con la evaluación preoperatoria de nuestros pacientes para la detección del SARS-CoV-2 mediante pruebas de PCR, la evaluación y vigilancia postoperatoria, recomendaciones quirúrgicas como disminución de tiempos quirúrgicos, capacitación del equipo quirúrgico y cuidados de la vía aérea. Con el desarrollo de vacunas y con la inmunidad adquirida, fuimos y Reconstructivo.

Integrante del Comité de Seguridad de la

Asociación Mexicana de

Cirugía Plástica, Estética

y Reconstructiva.

México.
Citar como: Vélez-Benítez E. El renacimiento de la cirugía plástica. Cir Plast. 2021; 31 (3): 95-96. https://dx.doi. org/10.35366/103709 
adaptándonos a un renacimiento de esta pandemia; sin embargo, así como el virus muta con nuevas cepas como la delta u ómicron, continuaremos adaptándonos, aprendiendo y a no confiarnos.

Tal vez en años futuros seremos referencia y hablarán de nosotros por el tiempo en el que estamos viviendo; mientras, continuaremos aprendiendo y mejorando técnicas quirúrgicas en la era de la pandemia, de la cual ya hemos renacido.

\section{Correspondencia:}

Dra. Estela Vélez-Benítez

Tlacotalpan No. 59, Col. Roma Sur, 06700,

Ciudad de México, México.

E-mail: cirugiaplastica@draestelavelez.com 